УДК 334.72

DOI: 10.14451/1.195.82

\title{
ТРАНСФОРМАЦИЯ ТРАДИЦИОННЫХ БИЗНЕС-МОДЕЛЕЙ В ЭКОСИСТЕМЫ БИЗНЕСА В РОССИИ
}

\author{
(C) 2021 Кочетова Маргарита Вячеславовна \\ студент \\ Самарский государственный экономический университет, Россия, Самара \\ E-mail: margo8090@mail.ru \\ (c) 2021 Евдокимов Анатолий Николаевич \\ кандидат экономических наук, доцент \\ Самарский государственный экономический университет, Россия, Самара
}

Сегодня лидирующие позиции и признание клиентов добиваются компании, которые «отошли» от традиционных бизнес-моделей, когда в качестве инновационной формы ведения бизнеса считается концентрация на один вид услуги или продукта. Сейчас все чаще наблюдается переориентация организации на более сложную структуру, на более развитую, когда целью деятельности становится - распространиться на разные области, не фокусируясь на каком-то одном направлении. Такая бизнес-модель называется экосистемой бизнеса, то есть набором собственных или партнерских сервисов, объединенных вокруг одной компании [1]. В данном исследовании рассмотрено, как бизнес-модели трансформируются в экосистемы, почему это актуально сегодня, приведены примеры действующих экосистем бизнеса в России и алгоритм стратегической реализации экосистемы на практике.

Ключевые слова: экосистема бизнеса, организация, бизнес-модель, развитие, трансформация, продукты, система, анализ, модернизация.

\section{Основные положения:}

- В современном мире традиционные бизнес-модели стали активно преобразовываться в экосистемы - когда компании, с помощью поглощения других, становятся шире и распространяют свои продукты и услуги на все сферы жизни общества.

- Две самые крупные экосистемы бизнеса в России «Яндекс» и «Сбербанк» получили свое признание благодаря быстрым, безопасным и простым сервисам, упрощающих повседневные действия клиентов.

- Чтобы компании произвести трансформацию в бизнес-экосистему, ей нужно следовать выстроенному алгоритму, благодаря которому она постепенно будет развиваться и эффективно функционировать.

\section{Введение}

В чем состоит сущность компании в традиционном видении? Это организация, занимающаяся каким - то одним профильным бизнесом, осуществляющая деятельность в рамках одного направления. Но конкуренция на рынке с каж- дым годом растет, а требования клиентов становятся более завышенными, ориентируются на инновации, на упрощение традиционных основ жизни. Эти изменения побуждают компании разрабатывать новые бизнес-модели и стратегии, которые позволяют им быстрее адаптироваться к постоянно меняющимся рыночным условиям. Бизнес-экосистемы - одно из решений этой проблемы, поскольку они предлагают новый, более гибкий способ организации бизнеса, привлекая различных партнеров, которые позволяют компании получить доступ к большему количеству возможностей и быстрее развиваться. Партнерам, в частности, рекомендуется создавать долгосрочные отношения с компанией, поскольку крупные компании имеют свои сильные стороны, но также и недостатки, которые могут быть дополнены возможностями партнера. Бизнес-экосистемы могут создать множество стратегических возможностей и операционных преимуществ для крупных компаний. В рамках экосистемы организации могут обмениваться ресурсами друг с другом и создавать новые возможности для бизнеса. 


\section{Методы}

В качестве основного метода исследования авторами был использован анализ актуальной информации на 2020 и 2021 года по развитию бизнес-экосистем в России и мире: прессрелизы, материалы СМИ, интервью и публичные выступления топ-менеджеров, сайты и приложения компаний, презентации для инвесторов, анализ научной литературы по исследованиям в области бизнес-моделей («Бизнес-модели: 55 лучших шаблонов» Оливер Гассман, «Бизнес 21 века Роберт Кийосаки). Также применялись методы изучения и обобщения статистических данных, сравнение традиционных бизнес-моделей с бизнес экосистемами, наблюдение использования компаниями экосистемы бизнеса и их популярность среди потребителей.

\section{Результаты}

В России самыми крупными компаниями, работающие по модели экосистемы являются: «Яндекс», «Сбербанк», MTС, «Тинькофф», Mail. ru Group. В ходе исследования были выявлены следующие результаты анализа появления этих бизнес-экосистем в России:

На примере двух самых крупных в России экосистем бизнеса «Яндекс» и «Сбер» авторы рассмотрели процесс трансформации этих компаний от традиционных бизнес-моделей в экосистемы. Яндекс - российская транснациональная компания в отрасли информационных технологий, корпорация с большим количеством сервисов и активов. История Яндекс началась в 1989 году и долгое время компания позиционировала себя как поисковая система. После покупки акций компании Сбербанком Яндекс стал расширять свою деятельность: с 2015 года компания разработала собственную технологию прогноза погоды, которая строит прогнозы с высокой точностью, появился «Яндекс-дзен», развивались образовательные проекты, транспортные проекты. Вскоре в 2017 году Яндекс создал голосовой ассистент Алиса, были запущены различные платформы для бизнеса. Предположительно, что до 2018 года Яндекс работал по традиционной инновационной бизнес-модели, которая позволяла совершенствовать продукт и достигать его признания среди потребителей (в 2001 году компания победила своего главного конкурента «Рамблер», с каждым годом модернизировалась сама поисковая система, появлялись новые сервисы, упрощающие поиск в ин- тернете). А в 2018 Яндекс стал ярким примером российской экосистемы бизнеса, охватывающей все стороны жизни людей. За этот год этой компании удалось объединить в себе такие сервисы, как «Яндекс. Облако», «Яндекс. Диалоги», «Яндекс. Плюс», «Яндекс. Драйв», «Яндекс. Заправки», «Яндекс. Такси» с помощью поглощения других компаний (например, «Яндекс Еда» образовалась из компании «Foodfox») [2]. Почему сегодня люди активно пользуются сервисами Яндекс? Согласно опросам, Яндекс браузер привлекает людей быстрым и безопасным поиском в интернете, ещё одной отличительной чертой Яндекс браузера является его интеграция с основными сервисами от Яндекс (Яндекс.Почта, Яндекс.Переводчик, Яндекс.Афиша, Яндекс. Дзен, Яндекс.Новости и т д), всего насчитано 100. Все эти сервисы упрощают работу в интернете, в том числе развития своих мини-сайтов, которые сейчас реализуются в системе Яндекс. Дзен. Она позволяет любому человеку распространить свой блог по актуальным темам, которые при забивании в адресной строке запроса, высвечиваются первыми. Таким образом можно привлечь массовую аудиторию, которая будет распространять эти статьи, создавая платформу для бизнеса. В 2019 году дневная аудитория была на 50\% меньше [3]. Число активных блогеров в 2020 году - 45 тысяч. Пользователи проводят на платформе 45 минут в день, 80\% времени связано с публикациями блогеров. За 2020 год Яндекс.Go стал ведущим сервисом по доставке еды в России, тем самым предоставив массу рабочих мест курьерам со свободным графиком и достойной заработной платой, а потребителям быстро заказать еду из любимого ресторана. Более того, Яндекс.Go представляет собой не только сервис по доставке еды, но и включает в себя услуги такси разного уровня (эконом, премиум, люкс, бизнес), каршеринга, курьерской доставки посылок.

ПАО «Сбербанк» - российский финансовый конгломерат, крупнейший транснациональный и универсальный банк России, Центральной и Восточной Европы [4]. На 2014-2018 года «Сбербанк» выстроил следующие элементы бизнесмодели: выстраивание отношений с клиентами через все возможные каналы (отделения, мобильный банк, банкоматы и т.д.), чтобы им было максимально удобно пользоваться Банком; выстраивание максимально доверительных отношений с клиентом за счет понимания 
его потребности, сделать продукты и услуги Банка важной частью для жизни каждого клиента; закрепить лидерские позиции Банка через основные каналы привлечения клиентов [5]. Так в 2020 году «Сбербанк» не стал останавливаться на реализации всех стратегий, описанных до 2018 года, сделал ребрендинг, превратившись в «Сбер», и новые стратегии теперь ориентируются не только на финансовую сферу и привлечения розничных клиентов. Сегодня компания «Сбер» одна из крупнейших экосистем в России, предлагающая услуги по финансам, шоппингу, досугу, здоровью и бизнесу. «Дом клик» от Сбербанка - портал по недвижимости, позволяет быстро и по всем необходимым параметрам найти квартиру клиенту и заодно оформить ипотеку онлайн на нее без похода в банк. Лидером среди порталов поиска вакансий стал сервис Работа.ру, с помощью интеграции со Сбербанком портал усовершенствовался, в результате чего сейчас на сайте размещено более 480 тыс. объявлений о вакансиях. Сервис удобен и безопасен, благодаря тому что все работодатели реально существуют и действуют в соответствии с законом [6]. Многими другими сервисами, ставшими в результате поглощения «Сбербанком» популярными и модернизированными, активно пользуются клиентами по всей России. То, насколько быстро «Сбербанк» преобразовывался в экосистему говорит диаграмма 1.

Изучение истории и последовательности развития экосистем бизнеса на примере «Яндекс» и «Сбербанк» показало, что важным эта- пом трансформации компании в экосистему является стратегия, ориентированная на упрощение уже имеющихся продуктов и услуг и их повсеместное распространение в каждой области потребления.

Согласно процессу развития экосистем в России, авторами был выделен следующий алгоритм действий для трансформации компании в бизнес-экосистему преимущественно для этой страны:

1 шаг. Для того чтобы компании расшириться и создать экосистему, сначала нужно определить, в каком направлении ей следует двигаться и какие потребительские проблемы решать. На данном этапе важно оценить состояние потребностей потенциальных клиентов, их возможности, состояние самой компании, примерно рассмотреть пути развития компании, а именно, какие области жизни важно для любого человека упростить или убыстрить, проанализировать состояние конкурентной среды, различных отраслей, спроса и предложения.

2 шаг. На этом этапе нужно выбрать конкретные направления для развития компании, исходя из анализа рынка, своих возможностей. И решить, какими методами и с помощью каких ресурсов можно добиться реализации поставленной цели. Здесь также следует выбрать потенциальных партнеров, которые готовы будут сотрудничать с компанией, или тех, кого возможно «поглотить». Благодаря возможностям цифровой и технологической среды, компания может реализовать удовлетворение этих по-

Количество сервисов в экосистеме Сбер

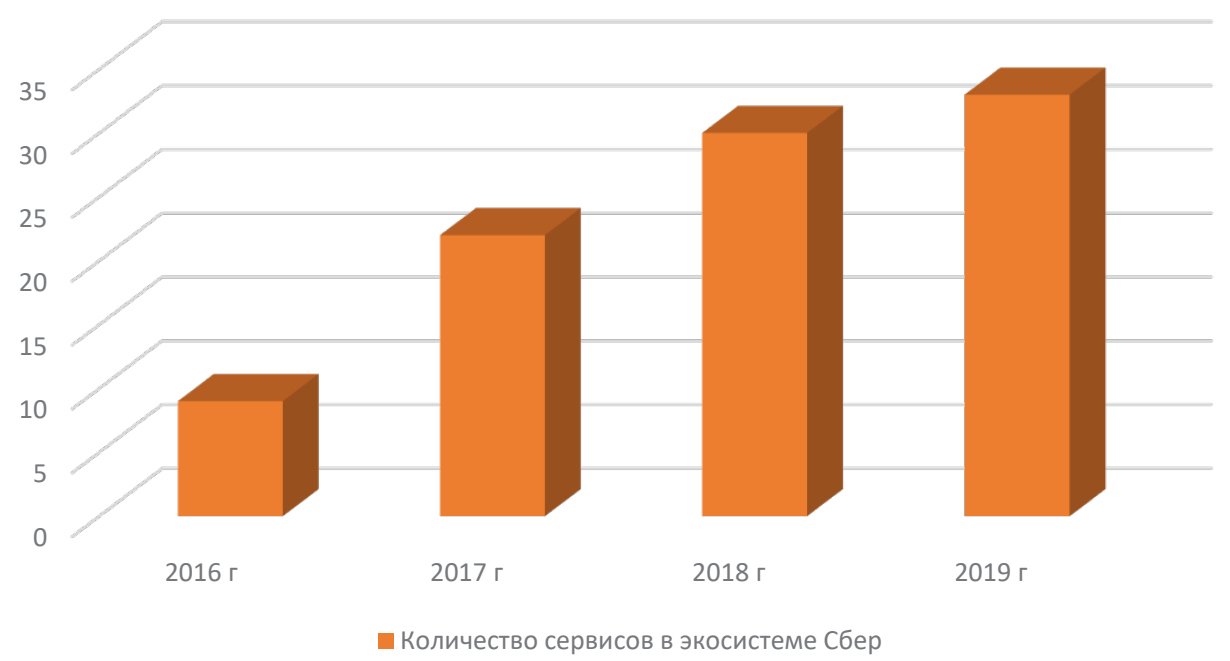

Диаграма 1 
требностей с помощью мобильных приложений, это также нужно учесть.

3 шаг. Выбор модели управления обязателен для экосистемы бизнеса. Именно поэтому на данном этапе нужно провести собрание с партнерами, всем руководящим составом организации, акционерами, и решить, какой вид управления должен быть использован в будущей экосистеме. На этом этапе нужно понять, какие полномочия и ответственность будет у каждого из партнеров, как будет распределяться прибыль, как будет производиться контроль над каждым подразделением.

4 шаг. На данном этапе следует сформулировать ценностное предложение для клиента, можно продемонстрировать ему о кардинальных изменениях и увеличении компании, например, сделать ребрендинг, как «Сбербанк», донести до покупателя разделение с ним его ценностей, определяя ценностное предложение для каждой группы соответствующих заинтересованных сторон.

Шаг 5. Здесь нужно сформулировать стратегию монетизации каждого направления деятельности компании, чтобы в случае «прогорания» какого-то из них, окупилась хотя бы малая часть его разработки. Это можно сделать с помощью стимулирования клиента оплатить первую покупку со скидкой. Нужно оценить, как клиент захочет пользоваться услугами сервиса, что сподвигнет его заплатить в дальнейшем за услугу. Это также исходит из учета его ценностей. Например, сервис онлайн кинотеатр «Окко» от «Сбер» является лидером по платной модели монетизации, это достигнуто благодаря возможности смотреть любой фильм в лучших форматах качества, рациональной рекламе сервиса, большим выбором фильмов, возможности выбрать 6 разных подписок в зависимости от потребностей.

Шаг 6. Решить, где географически возможно запустить тот или иной продукт, оценить потери, если его не получится реализовать в определенной области. Иногда следует ограничиться одним городом, чтобы понять, будет ли работать система или нет.

Шаг 7. Реализация продуктов или услуг, разработка всех их составляющих и запуск в действие.

\section{Обсуждение}

История возникновения экосистемы бизнеса началась с ведения термина «экосистема», который был введен британским ботаником Артуром Тэнсли, который использовал его для описания сообщества организмов, взаимодействующих друг с другом и с окружающей их средой: воздух, вода, земля и т.д. Чтобы существовать, организмы конкурируют и сотрудничают друг с другом в зависимости от доступа к ресурсам, совместно эволюционируют и совместно адаптируются $\mathrm{k}$ внешним условиям. А в 1993 году Бизнес-стратег Джеймс Мур использовал эту биологическую концепцию для определения бизнеса. Он сравнил жизнь компаний с организмами, которые также адаптируются и конкурируют, чтобы суметь существовать [7]. Мур предложил рассматривать компанию не как отдельную фирму в отрасли, а как члена бизнес-экосистемы с участниками из разных отраслей.

Существует большое количество бизнес-моделей, которые постепенно формировались, когда инновационная компания транслировала свои продукты и методы их потребления. Их принято называть традиционными, так как после их образования у них появилось много последователей, которые по всему миру использовали ту или иную бизнес-модель. Например, модель «Лизинг» была сформулирована компанией Хеrox, деятельность которой заключалась не в продаже своих продуктов, а в сдаче в аренду оборудования, после этого повсеместно были открыты компании, позволяющие брать в аренду автомобиль и платить только за время, которое было использовано клиентом (каршеринг). Компания YouTube использует модель Freemium, с помощью которой можно пользоваться данной программой бесплатно, а именно размещать видео и монетизировать свой влог. Но все эти модели, как правило, были использованы компаниями для развития какой-то одной области потребления. Экосистема позволяет использовать все те же традиционные модели, но для разных аспектов бизнеса и тем самым объединять их в одну компанию.

Экосистемы охватывают сразу несколько важных сфер жизни общества (транспорт, торговля, развлечения, финансы, шоппинг, здоровье, бизнес и т д), при этом создавая усовершенствованную систему потребления услуг и 
продуктов для клиента. Экосистема требует постоянного развития, диверсификации деятельности компании, достижение высокого качества сервиса и продукции во всех ее областях.

Рассуждение на эту тему ярко представлено в статье «Инновационные отношения в условиях появления финтех-экосистем» К., Ляхтеенмяки, И., и Сеппянена, М. Они высказывают мысль о том, что компании из большинства секторов перешли от конкуренции за эффективность и результативность к конкуренции за постоянные инновации, и они заметили, что делать это в одиночку становится все труднее. Вместо этого они должны совместно развиваться, преодолевая свои границы, поскольку ни одна компания, независимо от ее размера, не обладает всеми необходимыми знаниями и ресурсами для этого изменения [8]. Таким образом, компании обращаются к традиционным бизнес-моделям и заменяют иерархически управляемые цепочки создания стоимости внутри экосистемных моделей, которые по своей структуре более модульные и децентрализованные.

Бизнес-экосистемы требуют от компаний стратегического мышления. Чтобы создать экосистему бизнеса и объединить несколько бизнесмоделей в рамках одной компании, следует принять множество стратегических и оперативных решений. Компания должна тщательно планировать, как вовлечь своих партнеров в процесс создания ценности, и принять решение о роли, которую она хочет играть в экосистеме.

Автор научных статей, экономист, рассуждающий на тему бизнес-экосистем, Майкл Дж.Якобидес говорит о том, что компании должны создавать совместные ценности в эко- системах. Чтобы экосистема приносила пользу всем участникам, головная компания не может концентрироваться только на инновациях, важно понимать, как помочь партнерам создавать ценности. Часто компании, входящие в экосистемы, добивались этого, расширяя собственное ценностное предложение, комбинируя свое основное предложение с каким-либо ранее не связанным продуктом или услугой [9]. Это может означать, например, что партнеры начинают предлагать своим клиентам некоторые совместно созданные услуги.

Так, авторы-публицисты доказывают мысль о том, что трансформация традиционных бизнес-моделей компаний в экосистемы, невозможна без создания совместной структуры ценностей, а также осознания этих ценностей для потребителей.

\section{Заключение}

Таким образом, рассмотрев примеры трансформации традиционных моделей бизнеса в бизнес-экосистемы в России, был сформулирован алгоритм создания экосистемы для компании. Проанализировав опыт зарубежных и российских компаний, можно сделать вывод, что именно экосистема сегодня стала лидирующей моделью ведения бизнеса, которая позволяет совместить в себе несколько традиционных бизнес-моделей и усовершенствовать их работу с помощью создания системы ценностей для каждого участника, в том числе для клиента. В построении экосистемы важен не только ценностный ориентир, но и правильно вытроенная стратегия, на которую следует фокусироваться в процессе разработке данной модели.

\section{Библиографический список}

1. https://ru.wikipedia.org/wiki/

2. История «Яндекс» [https://ru.wikipedia.org/wiki/]

3. Статистика пользователей «Яндекс.Дзен» [https://vc.ru/media/186520-45-tysyach-blogerov-i-20-mlnpolzovateley-v-den-yandeks-dzen-podvel-itogi-goda-i-rasskazal-ob-obnovleniyah-platformy]

4. Определение ООО «Сбербанк» [https://ru.wikipedia.org/wiki]

5. Стратегия развития «Сбербанк» 2014-2018 [https://www.sberbank.com/common/img/uploaded/ir/docs/sberba nkdevelopmentstrategyfor2014-2018_ru.pdf]

6. Экосистема «Сбер» [https://www.sberbank.com/ru/eco]

7. Джеймс Ф. Мур Бизнес «Хищники и жертвы: новая экология конкуренции» 1993

8. Джеймс Ф. Мур Бизнес-экосистемы и взгляд фирмы 2006

9. Майкл Дж. Якобидес Какова ваша стратегия в экосистемной экономике? Пять вопросов, на которые вам нужно ответить Из журнала Harvard Business Review Home (сентябрь - октябрь 2019 г.)

10. К., Ляхтеенмяки, И., и Сеппянен, М. (2019) Инновационные отношения при возникновении финтехэкосистем. В материалах 52-й Гавайской международной конференции по системным наукам

11. Минг Зенг "Умный бизнес: что успех компании Alibaba приоткрывает о будущем стратегии" 2018

12. Oliver Gassmann, Karolin Frankenberger and Michaela Csik, 2014 